Article

\title{
Cities' Greenhouse Gas Accounting Methods: A Study of Helsinki, Stockholm, and Copenhagen
}

\author{
Karna Dahal * and Jari Niemelä \\ Department of Environmental Sciences, University of Helsinki, P.O. Box 65 (Viikinkaari 1), 00014 Helsinki, \\ Finland; jari.niemela@helsinki.fi \\ * Correspondence: karna.dahal@helsinki.fi; Tel.: +358-44-513-1755
}

Academic Editor: Yang Zhang

Received: 4 March 2017; Accepted: 30 March 2017; Published: 3 April 2017

\begin{abstract}
Cities generally adopt territorial- or production-based rather than consumption-based emissions accounting systems but they find difficult to adopt a specific emissions standard. Due to the diverse calculation methodologies cities use, inter-city emission reductions and climate action comparisons remain challenging. It is crucial to learn how cities address climate change mitigation and adaptation in terms of the emissions accounting methodologies they use, their links to existing city-level international emission standards, and the consistency of those methods used by cities to improve the quality of emissions standards. Normative case study method was applied to explore these issues in three different case cities: Helsinki (Finland), Stockholm (Sweden), and Copenhagen (Denmark). The current calculation methods used in these cities exclude many indirect emissions, and these cities have not adopted consumption-based emissions. Cities also face several dilemmas in system boundaries and baseline year setting, emissions factors calculations, and data collection methods using current calculation methods. All three case cities have adopted amendable emissions accounting systems which exclude certain amounts of emissions from several sectors. Therefore, emission calculation methods must be improved to include all possible sectors and to produce more robust and transparent calculation methods.
\end{abstract}

Keywords: GHG accounting system; emissions reductions; climate strategies; emissions sources; consumption-based emissions

\section{Introduction}

Significant reductions in anthropogenic greenhouse gas (GHG) emissions are vital to mitigating the consequences of global warming and climate change [1]. Cities are key to reducing GHG emissions since more than $70 \%$ of global energy-induced emissions are generated in cities [2,3]. Cities' GHG emissions strategies are normally based on country-level strategies, although several cities have adopted their own strategies aimed at GHG reductions [2,4]. Similarly, cities are also vulnerable to the consequences of climate change since most are located along coastal areas, placing them at risk of flooding from rising sea levels and storms [3,4]. Cities' well-defined climate strategies represent one effective measure to reduce GHG emissions produced within their territories. Identifying key emissions sources, implementing reliable emissions accounting systems, and reversing emissions trends all serve to establish strong climate strategies. Cities' main GHG sources stem from building (residential, commercial, and industrial) heat and electricity, road transport, shipping, freight transport, fuel processing, energy industries, waste and water treatment plants, industrial factories, agriculture, food processing, and logistics [5]. In general, the GHG emissions of a single city are small compared with emissions at the national or regional levels. Yet, city-level strategies support and complement national GHG reduction goals and fulfill local climate mitigation and adaptation responsibilities. Thus, cities should adopt robust, transparent, and justified carbon emissions accounting systems. 
Such accounting systems help cities to plan strong and effective climate goals. However, they require clear guiding principles for adopting single such accounting system [6].

Multiple cities formulate and implement climate actions using different GHG accounting methods, while the reliability and appropriateness of such methods remain unknown [6]. These methods contain uncertainties regarding data measurement, data collection, and calculation methodologies [7]. Their emissions accounting systems originating from national-level perspectives based on a standardized calculation framework provided by the Intergovernmental Panel on Climate Change (IPCC) [8] and the United Nations Economic Commission for Europe (UNECE) Convention on Long-Range Transboundary Air Pollution (LRTAP) $[9,10]$. Such accounting systems generally function well enough within the United Nations Framework Convention on Climate Change (UNFCC) and for the annual report of UNECE member states, but do not work well at the city level $[1,3,8]$. However, the Network of the World's 40 Megacities (C40 group), the World Resources Institute, and local Governments for Sustainability (ICLEI) recently established a GHG standard for cities called the Global Protocol for Community-Scale Greenhouse Gas Emissions Inventories (GPC) [11]. GPC aims to ensure consistent and transparent international measurement and reporting of GHG between cities [11]. It has been piloted in many cities, and several cities have already begun using it to establish comprehensive and robust GHG inventories of their emissions [11,12].

In general, three different emissions accounting systems spanning the coverage and scope of emissions are available to cities [9]. Cities typically adopt territorial- or production-based rather than consumption-based accounting systems [9]. Territorial-based accounting systems calculate emissions occurring within one's borders and offshore areas falling under the jurisdiction of a region or country [9]. These types of systems do not reflect emissions from national and international trade [13]. Production-based accounting systems measure the emissions from economic activities (production) by resident companies and households in specific sectors regardless of where these activities take place [9]. The only difference between production- and territorial-based emissions accounting systems is where the emissions are generated. Territorial based-emissions consist of emissions from a city's land and offshore areas falling under the city's jurisdiction, whereas production-based emissions may include emissions generated beyond the city's boundaries related to the economic output of companies physically situated within that city [9]. Similarly, consumption-based accounting methods consist of emissions generated from the consumption of goods and services within an area regardless of where the production of such goods and services resulted in emissions [9]. Currently, no international regulations exist which require the reporting of consumption-based emissions and, thus, cities have not adopted this method [9]. However, consumption-based accounting systems cover all emissions resulting from the consumption of local and imported goods and services, and are, therefore, considered more comprehensive calculation methods than production- and territorial-based models [9]. The GPC standard outlines three scopes for emissions calculation standards [2]. Scope 1 extends to territory-based emissions and covers emissions from sources located within the city boundaries, while scope 2 includes grid-supplied energy which may or may not cross city boundaries [2]. Scope 3 includes all indirect consumption-based emissions excluding those included in scopes 1 and 2, but includes all indirect emissions occurring beyond the city boundary as a result of activities taking place within the city [2] The total sum of emissions falling within scopes 1, 2, and 3 refers to the carbon footprint or consumption-based emissions of a city [14].

All of the above-mentioned emissions accounting systems provide the means via which cities might calculate their emissions and establish future climate strategies; but they also leave cities puzzled regarding the selection of the appropriate emissions accounting system. Many cities, including Nordic cities, have adopted emissions calculation standards using their own principles, which are somewhat different from the emissions accounting systems described above [15-17]. Similarly, a variety of emissions calculation methods may exist within a single city [16-18], while no emissions standard regulations are available to cities at the national level. This makes it more difficult for cities to adopt a 
specific emissions standard. Due to the various calculation methodologies used by cities, comparing inter-cities' emissions reductions and climate actions remains difficult.

Cities face additional challenges, such as limited data acquisition compared to national-level data, difficulty defining a city's jurisdictional boundaries for emissions calculations, avoiding inappropriate calculations, and excluding several important city-induced emissions [3]. In addition, cities face multiple difficulties accessing data from private companies and deciding what level of air traffic and interurban commuting falls within the scope of calculations [3]. When territorial- and production-based calculations are applied, cities do not include emissions derived from goods imported from abroad or from beyond city borders, nor do they consider waste disposal outside city borders [3]. Recent results demonstrated that consumption-based emissions are increasing while production- or territorial-based emissions are decreasing in the European Union and Organization for Economic Cooperation and Development (OECD) countries [19]. This increases the importance of consumption-based emissions accounting systems and challenges in establishing the baseline year for an emissions reductions strategy. Major cities typically annex several other small cities, yet the lack of formal cooperation across such cities poses challenges for setting emissions accounting boundaries and climate strategies. Such problems exist in metropolitan areas in various countries.

Many cities globally have not yet attempted emissions inventories, posing difficulties related to generating estimates for the scale of city-generated emissions worldwide [20]. Several Nordic cities, however, have adopted inventories for their emissions calculations. The cities of Helsinki, Copenhagen, and Stockholm represent leaders in climate change adaptation and mitigation, and are working intensely to reduce carbon emissions. This paper investigates how these cities are working towards climate change mitigation and adaptation in terms of the emissions accounting methodologies they use, their links to existing city-level international emissions standards, and the consistency of these methods. One reason we selected these cities is that they feature better practices related to emissions accounting systems than other municipalities within each country. In addition, most municipalities in the Nordic countries have adopted similar emissions accounting systems as those existing in their capital cities $[16,17]$. The capital cities have also clear climate strategies to become carbon neutral (Helsinki by 2050 and Copenhagen by 2025) and fossil fuel free city (Stockholm by 2040) [21] which needs transparent and robust GHG emissions accounting system. This paper also assesses the suitability of the IPCC and GPC methodologies for the climate strategies defined by these three cities. To do so, we use a case study method which includes interviews with each city's climate authorities. Through this study, local governments and city authorities can review their emissions accounting methods and consider developing a strong, wide-reaching emissions accounting system to address their future climate strategies.

\section{Methods}

We applied a normative case study method to analyze the emissions accounting systems used in three different cities: Helsinki (Finland), Stockholm (Sweden), and Copenhagen (Denmark). As a typical approach, the normative case study represents a descriptive study of specific cases with a normative aspect allowing for the identification of improvements [22]. It combines empirical observation with assessment, and is particularly useful for analyzing complex ethical concepts that carry both descriptive and evaluative dimensions [23]. The normative case study approach recognizes the difficulties and problems within cases and ultimately helps shape corrections using sound judgment to build the foundation for improvements to existing cases [22]. We applied this method to compare and contrast the emissions calculation methodologies used in our case study cities in relation to current existing city-level international accounting systems, such as the GPC and IPCC methodologies. To complement the normative comparisons, we conducted semi-structured interviews in two cities: Helsinki and Copenhagen. While an interview in Stockholm was not possible, we received the necessary information and documents for this study via email. 
While we focused on specific themes or topics during the interviews, the exact wording depended upon the specific interview context. We interviewed two individuals: Johannes Lounasheimo (Helsinki Region Environmental Services Authority (HSY)) and Morten Højer (City of Copenhagen). In Helsinki, HSY developed the emissions accounting system, and calculates emissions in the metropolitan region, which includes other municipalities in the Helsinki metropolitan area. In addition, we also discussed various issues with the three other individuals from the city of Helsinki: Sonja Maria Ignatius, Petteri Huuska, and Jari Viinanen. Similarly, we conducted an interview with Morten Højer from the city of Copenhagen to collect information about the emissions accounting system used in Copenhagen, since the city developed its own accounting system and calculates its emissions. These interviews enabled us to acquire background information on past and currently applied emissions calculation methodologies, their future plans towards improving these methodologies, and current and future climate strategies based on the methods applied in each city. The interviews with city representatives also allowed us to understand problems associated with collecting and calculating emissions data, setting the city boundaries, and defining the sectors included in emissions calculations. The normative case study method also provided us with opportunities to explore conditional explanations of the emissions calculation methods used in each city and at the international level as well as to explore possible improvements to future emissions accounting systems in three Nordic capital cities.

\section{Results}

\subsection{Emissions Accounting Methodologies in the Case Study Cities}

The calculation of GHG emissions in all three case cities is based on statistics collected at both the national and local levels [15-17]. Copenhagen and Stockholm have adopted a production-based emissions accounting system similar to scope 1 from the GPC standard [15,17], while Helsinki adopted a territorial-based emissions accounting system similar to scopes 1 and 2 from the GPC standard $[16,18]$. However, the emissions calculations for the use of electricity in all three cities are based on consumption, while waste treatment in Helsinki is based on production.

The city of Stockholm currently uses a computational emissions calculation system. In doing so, it calculates the emissions from space heating, total electricity (including cooling) consumption, and transportation within the city limits [16]. All of these sectors are further divided into subsectors. For instance, the heating sector is divided into district-level and individual heating. Several datasets in Stockholm are difficult to separate from national-level data and some statistics are not available at the municipal level [15]. Similarly, several sets of statistics are not entirely transparent. For instance, statistics for oil use, individual heating, and emissions from the production and distribution of goods used in the city remain unclear [15]. Thus, Stockholm calculates emissions for carbon dioxide $\left(\mathrm{CO}_{2}\right)$, nitrous oxide $\left(\mathrm{N}_{2} \mathrm{O}\right)$, and methane $\left(\mathrm{CH}_{4}\right)$ [15].

The city of Helsinki adopted the Hilma model for emissions calculations. This model is based on a municipal-level emissions calculation model previously used in Finland called KASVENER $[16,18]$. Hilma, an improvement over the KASVENER emissions calculation model, was developed by HSY to calculate the emissions for the Helsinki metropolitan area [16]. However, the carbon footprint of the Helsinki population was calculated using the KASVENER model [18]. Similar to Stockholm, Helsinki calculates emissions for carbon dioxide $\left(\mathrm{CO}_{2}\right)$, nitrous oxide $\left(\mathrm{N}_{2} \mathrm{O}\right)$, and methane $\left(\mathrm{CH}_{4}\right)[16,18]$. Some input data used in the Hilma model represent estimates rather than accurate figures, such as the amount of heat used in buildings beyond the district heating network [16]. The system boundaries in the Hilma model are somewhat consistent with scopes 1 and 2 in the GPC standard [16]. Energy sector-related emissions are consumption based, while all other sectors are either territorial or consumption based [16].

The city of Copenhagen calculates its emissions using a web-based calculation tool, the $\mathrm{CO}_{2}$ emissions calculator, specifically designed for municipalities in Denmark by the National Environmental Research Institute (NERI) and COWI, an international consulting company $[15,17]$. 
The $\mathrm{CO}_{2}$ emissions calculator can process different levels of data based on their precision and availability [24]. Thus, incomplete data may be used, but the results will reflect an average [24]. Furthermore, this calculator may also include strategic data for future climate strategies. For instance, emissions data may be used for the future establishment of wind farms [24]. The $\mathrm{CO}_{2}$ emissions calculator applies national emissions factors for electricity consumption, and includes emissions from the renewable energy adjustment category not available in the GPC standard or other accounting mechanisms [25].

The current calculation methods used by the cities exclude many indirect emissions such as life cycle emissions, emissions from the extraction and production of purchased materials and fuels, transport-related activities in vehicles not owned or controlled by cities, electricity transmission and distribution losses, outsourced activities, and a few waste disposal actions. Table 1 provides information on the direct emissions sources included and excluded by cities in their emissions calculation methods.

Table 1. Direct emissions sources included in and excluded from the current calculation methods by city [15-17].

\begin{tabular}{cll}
\hline \multicolumn{1}{c}{ City } & \multicolumn{1}{c}{ Included Emissions Sources (Sectors) } & \multicolumn{1}{c}{ Excluded Emissions Sources (Sectors) } \\
\hline Helsinki & $\begin{array}{l}\text { Heat and electricity (consumed), transportation, } \\
\text { industry, ships in harbor, worksite vehicles (fuel), } \\
\text { waste, wastewater, and agriculture }\end{array}$ & $\begin{array}{l}\text { Air traffic, long distance trains, forestry, solvents, } \\
\text { and refrigeration }\end{array}$ \\
\hline Copenhagen & $\begin{array}{l}\text { Heat and electricity (consumed), individual heating, } \\
\text { transportation, and waste }\end{array}$ & $\begin{array}{l}\text { Land use change (LUC), refineries and flaring, } \\
\text { agriculture, forestry, fisheries, solvents, and air travel }\end{array}$ \\
\hline \multirow{3}{*}{ Stockholm } & $\begin{array}{l}\text { Space heating, total electricity consumption (includes } \\
\text { cooling), transportation, work machineries, leakage } \\
\left.\text { of city gas, refrigeration, hospital emissions ( } \mathrm{NO}_{2}\right), \\
\text { shipping, airport emissions, freight traffic emissions, } \\
\text { and production of fuels used in the city }\end{array}$ & $\begin{array}{l}\text { Industries (very few industries), agriculture (very } \\
\text { little agriculture), waste management, and travel }\end{array}$ \\
\hline
\end{tabular}

Table 1 summarizes what cities included and excluded in their emissions depending on their emissions sources, calculation methodologies, and climate strategies. All of the cities included emissions resulting from major sources such as district heating, electricity consumption, and transportation (Table 1). Yet, cities excluded various emissions depending on the emission sectors. For instance, Stockholm does not house many industries nor agricultural production, and thus excludes emissions from these sectors. The city of Copenhagen includes emissions data from cruise ships from larger ships only [17]. Emissions from several sources, such as refrigeration, freight traffic emissions, and city gas leakage emissions, remain unclear in the city of Stockholm. Yet, Stockholm includes in its calculations airport emissions reaching heights of $915 \mathrm{~m}$, but does not include clear figures on emissions resulting from small land vehicles [15]. In addition, emissions data from the transportation sector, particularly road transport and construction, are not qualitatively available for Stockholm. Similarly, emissions from electricity consumption in Stockholm remain unclear since Stockholm only calculates electricity consumption at the household level [15]. In Helsinki, uncertainties exist related to the amount of electricity used for heating in private housing units [16].

Stockholm excludes more than half of the indirect sources of emissions from residents and businesses [15]. Similarly, Copenhagen and Helsinki exclude such emissions. Additionally, all three cities exclude emissions from international transport and imported goods and services [15-17]. This indicates that consumption-based emissions are not taken into account. However, the city of Copenhagen recently adopted consumption-based emissions calculations according to the GPC standard [17]. Helsinki also developed a preliminary calculation using the KUHILAS tool developed by the Finnish Environmental Institute, a tool under development that resulted in a figure more than double the current GHG calculation [26].

Several dilemmas affect the calculation methods adopted by cities. For instance, determining whether emissions from any business activities generating emissions within cities are included in calculations causes difficulties. Similarly, deciding to include emissions extending beyond city limits 
along with other businesses that operate within city limits but generating emissions beyond city boundaries also poses problems. However, the city of Stockholm calculates emissions including business operations that cover the greater metropolitan area, but does not include in its calculations emissions from businesses situated beyond the city limits that produce emissions inside the city [15]. Nevertheless, Stockholm's calculations include all emissions from the production of energy both inside and beyond the city boundary [15]. In addition, Stockholm's calculations include the emissions from fuels produced and distributed outside the city boundary [15]. Similarly, the city of Copenhagen also includes in its calculations emissions from businesses extending beyond the city boundary [17]. It is also difficult to determine whether the city must select consumption- or production-based emissions for specific categories of emissions in their calculation methodologies [17]. For instance, emissions related to electricity production in Stockholm takes place largely beyond the city boundaries, while the emissions calculation relies on the amount of electricity consumed within the city [15]. Similarly, Helsinki and Stockholm adopted the same system for calculating the electricity produced outside their city limits $[15,17]$.

We also found that one to two of the cities faced difficulties when choosing data, system boundaries, and the baseline year for calculations, and all case cities found defining emissions factors difficult. Typically, electricity is consumed from various national and international grids; consequently, cities face difficulties calculating emissions factors. The city of Stockholm previously used a Nordic mix of emissions factors calculated as the average from the previous five years, but the city currently uses a Swedish mix as the reference for calculating emissions from electricity use [15]. However, both calculations are inaccurate [15]. Stockholm also faces difficulty in selecting the baseline year (1990) for emissions reduction because emissions in Sweden have fallen below the baseline year since 1999 due to the phase out of oil and an increased reliance on biofuels for district heating production [15]. Therefore, Stockholm established 2005 as its baseline year [15]. Similarly, the city of Copenhagen uses 2005 as its baseline year [27]. Copenhagen aims to be carbon neutral by 2025, reducing 1.2 million tons in GHG emissions by 2025 [27]. In addition, the city of Stockholm finds producing accurate data difficult due to GHG leakage from the city gas network, the handling of refrigerants, healthcare industries and services, and a few other industries [15,17].

Cities should update their choice of system boundaries, data sources, and emission factors from time to time [11]. This helps to improve the quality of data and the calculation method, but does not enable comparisons with its own emissions across consecutive years. For instance, the city of Helsinki updated its emissions factors for electricity consumption to improve the quality of data as emissions change over time $[16,28]$. In the same way, the city of Copenhagen experienced difficulties in choosing which emissions factors to include, while the qualities of the city's energy emissions productions vary year to year [17]. The exact amount of electricity used for heating and transportation in Stockholm remains unspecified [15], and Helsinki finds splitting the use of electricity between heating and other uses difficult [28]. Some heating methods are outdated, while some are currently more advanced. For instance, oil heating is outdated, while electric and district heating are more popular at present [15-17]. This adds to the difficulties in calculating emissions data and comparing results.

Cities should compare their calculation methods using other international emissions accounting systems to verify their standardizations. The city of Stockholm compares its calculation method to the Environmental Protection Agency (EPA)'s emissions accounting system [15]. Helsinki validates its data with national experts from the Finnish Environmental Institute, the Helsinki Environmental Center, and local energy companies during national discussions as well as with several projects at the European level [28]. Stockholm recognized that the EPA method calculates emissions from a greater number of emission sources than Stockholm's calculation method [15]. Stockholm also updates the input data based on new research. Similarly, cities need to review their emissions data. All three cities review their emissions data, although the statistics only become available 18 months after the current year ends in Stockholm [15] and about four to six months after the current year ends in Helsinki [18]. This results in a backlog of nearly two years in Stockholm and six months in Helsinki. GHG leakage occurs in all 
three case study cities, yet the cities lack proper monitoring systems to control it [15,17]. According to the GPC specific accounting systems, opportunities also exist in these cities to calculate individual sector emissions, such as household, transport, and industrial emissions, using a specific calculation method for that sector [11]. None of these cities have adopted such emissions accounting methods.

The city of Copenhagen recognizes that the $\mathrm{CO}_{2}$ emissions calculator is no longer effective for robust emissions calculations since it brings a double counting in its method. For instance, electricity data associated with utilities and heating data from district heating companies are double counted [17]. Thus, the city began piloting a GPC standard for reports using a basic category in 2015 [17]. The city recognizes that GPC is a better-formulated emissions accounting scheme than the $\mathrm{CO}_{2}$ emissions calculator because it includes almost all emissions and can allow comparisons with results from other cities [17]. The city also believes that all businesses should adopt a corporate emissions accounting standard, which they are adopting for their emissions calculations [17]. Similarly, HSY realizes that the Hilma method used in Helsinki is not perfect. This is particularly the case for emissions data resulting from electric heating, because it was developed more than 10 years ago when coal-fired condensing power was more extensively produced [16]. Thus, Helsinki calculates emissions data using a higher emissions factor for electricity consumption for heating [16]. For this reason, the Hilma calculation method is under development [27]. Similarly, Stockholm is also adopting a different emissions accounting method, such as the GPC standard, since the current emissions calculation method is 10 to 15 years old and needs updating [29].

The case cities also reported emissions from different sectors, which they themselves typically report [15-18]. Table 2 presents the cities' reporting sectors.

Table 2. Various sectors reported by case cities $[15,17,18,24,30]$.

\begin{tabular}{ll}
\hline \multicolumn{1}{c}{ City } & \multicolumn{1}{c}{ Sectors } \\
\hline Helsinki & $\begin{array}{l}\text { District heating, electric heating, electricity consumption, transportation, industry and machinery, treatment } \\
\text { of waste and wastewater, and agriculture. }\end{array}$ \\
\hline Stockholm & $\begin{array}{l}\text { Domestic shipments, electricity and heat, industrial combustion, industrial processes, residential and } \\
\text { commercial buildings, agriculture, waste, and other sectors. }\end{array}$ \\
\hline Copenhagen & $\begin{array}{l}\text { electricity consumption, district heating consumption, traffic and mobile sources, individual heating, town } \\
\text { gas, heating consumption, and other sectors. }\end{array}$ \\
\hline
\end{tabular}

All of our case study cities' accounting systems ignore large amounts of GHG data embedded in their consumption. They have also not adopted the GPC standard. This may result from the lack of regulations for emissions reporting requirements based on consumption. The GPC standard was expanded to consumption-based emissions to include scope 3 calculations and the basic ${ }^{+}$and expanded reporting level [25]. Yet, this standard does not include an RE (renewable energy) adjustment, but includes European Union Emissions Trading System (EU ETS). Details regarding the sector categories and reporting are higher in the GPC system than in any other methods adopted across these three case study cities. If emissions are calculated based on consumption, the city emissions levels would be much higher than those using the current calculation method. For example, Copenhagen's consumption-based emissions was four to five times higher than the production-based emissions in 2015 [25].

\subsection{Effects of Emissions Accounting Systems on Climate Strategies and Actions}

Cities' emissions accounting methods also affect their climate strategies and actions since such strategies and actions rely on careful analyses of emissions calculations results. Emissions calculations represent the first step in climate mitigation actions [31]. They provide information on the amount of emissions in different sectors and a clear understanding of the level of climate strategies cities must adopt to reduce their calculated emissions.

Several cities and businesses have adopted compensation and offsetting measures to reduce emissions. Carbon offsetting consists of selling carbon credits in metric tons of carbon dioxide 
equivalents (tons $\mathrm{CO}_{2} \mathrm{e}$ ) through various measures, such as renewable energy, reforestation, and resource conservation [32]. Several cities in Japan and China have recently adopted such carbon offsetting measures [33,34]. For instance, the city of Tokyo adopted a cap and trade program for emissions offsetting from offices, commercial and public buildings, district heating, and cooling plants [33]. Similarly, some cities in China, such as Beijing, Chong-Qing, Guangdong, Hubei, Shanghai, Shenzhen, and Tianjin, recently initiated various emissions trading schemes for offsetting [34]. In the same way, compensation measures are adopted by cities to achieve their emissions reduction goals. Compensations typically involve creating carbon sinks—such as greenways, parks, gardens, green roofs, woodlands, waterways, community farms, forests, and wilderness areas [35] — and by producing renewable energy within and beyond city boundaries [32]. Among our case study cities, Copenhagen included emissions compensation from wind production beyond the city limits [17]. The other two case cities do not include such compensations in their calculations. However, Helsinki has identified this scheme as an option for fulfilling its total carbon reduction goal by 2050 and is considering using a carbon capture and sequestration (CCS) technology for emissions reduction [16,18].

Some states in the USA such as Maryland, California, and Colorado have adopted a carbon tax for emissions reductions [34]. Similar to carbon taxes, "congestion taxes" are also levied against gas-powered or high-emitting vehicles in European cities including London and Stockholm [34]. For several years, the city of Helsinki has studied the possibility of levying a congestion fee [36,37], specifically for emissions-producing vehicles on city-center roads while reducing fees for low carbon-emitting vehicles [18,38]. Cities' carbon taxes increase the cost of emitting carbon, whereby investing in production and the purchase of clean fuels, adopting low carbon-emitting behaviors, and reducing energy use become more attractive [34]. This will undoubtedly impact cities' strategies related to carbon emissions reductions.

Globally, cities also have additional opportunities to reduce emissions through the Global Covenant of Mayors. In total, 7100 cities from 119 countries around the globe have committed to this covenant [39]. As a voluntary program, cities can contribute their outstanding climate strategies, climate actions, and emissions accounting systems and compare their emissions data. In addition, they can establish common emissions accounting methods to include a wide range of emissions sources. All of the case study cities have committed to emissions reductions using this method [39]. As such, mayors adopted the initiative, and established the EU green capital award and URBACT 2014-2020 network, consisting of three other climate strategies and encouraging the commencement of programs in additional European cities [40].

Based on the emissions calculations using specific emissions accounting systems, cities identify the most and least significant sectors to prioritize for their emissions reductions and to establish climate strategies accordingly. For instance, Copenhagen's climate plan, CPH 2025 Climate Plan, aims at becoming carbon neutral by 2025 , and aims to reduce emissions from transportation, energy production, and energy consumption, while Stockholm's climate roadmap aims to a fossil fuel-free city by 2050 and targets to reduce emissions from transportation and district heating. Helsinki's climate roadmap has planned to reduce emissions from all sectors (Table 3). Table 3 presents the sectorial emissions reduction targets for Stockholm and Copenhagen and current emission distribution for Helsinki.

Table 3. Cities emission reduction targets in their climate plans $[16,25,38]$.

\begin{tabular}{ll}
\hline \multicolumn{1}{c}{ City' Climate Plan } & \multicolumn{1}{c}{ Sectors Requiring Emissions Reductions } \\
\hline Copenhagen climate plan & $\begin{array}{l}\text { Energy consumption }(7 \%), \text { energy production }(74 \%), \text { green mobility (11\%), city initiatives } \\
(6 \%), \text { and city administration }(2 \%) .\end{array}$ \\
\hline Stockholm climate road map & $\begin{array}{l}90 \% \text { emissions reductions from traffic by } 2020 \text { and } 100 \% \text { by } 2025, \text { and } 88 \% \text { direct and } 90 \% \\
\text { supplemental emissions reductions from district heating by } 2050 .\end{array}$ \\
\hline Helsinki climate road map & $\begin{array}{l}\text { Reduction requires from all sectors. However, current distribution is; } 60 \% \text { emissions from } \\
\text { heating, 20\% from electricity consumption, } 18 \% \text { from transportation, and } 2 \% \text { from } \\
\text { waste management. }\end{array}$ \\
\hline
\end{tabular}


More than one-third to one-fourth of the emissions reductions are targeted at energy production using renewables such as the installation of wind turbines and solar cells and switching from coal to biomass for heat and power plants in the city of Copenhagen [25]. A second area includes green mobility. This includes $70 \%$ aimed at reduction measures and $30 \%$ aimed at compensation measures [25]. However, Helsinki must reduce emissions across all sectors to achieve its carbon neutral goal by 2050 [16]. No quantitative data are availabe for sectorial emission reductions in Helsinki yet [16]. Stockholm has prioritized emission reductions from transportation and district heating. While it is important for cities to formulate stringent climate strategies to reduce significant emissions as per their calculation method, they should also consider other sustainability issues caused by the climate strategies. For instance, excessive use of biomass may lead to loss of biodiversity and changes in nutrient cycles in the soil [41].

\section{Discussion}

Our results show that cities' current emission calculations are not qualitatively nor internationally comparable. The diverse emission accounting methods adopted by cities bring inconsistencies in terms of the data quality and final results, thus complicating comparisons of their findings. Furthermore, the calculations affect the different timeframes for emissions-reducing activities, such as establishing the baseline year and determining the target year for carbon reduction. All three case cities adopted self-designed emissions accounting systems similar to national-level emissions standards, which are closely aligned with scope 1 or 2 from the GPC standard allowing for significant improvements to it. However, the emission accounting systems are based on EU and UN requirements for national-level emissions reporting. As such, all case study cities have a large amount of emissions from energy consumption and transportation, yet the nature and sectors of emissions depend on the fuels and energy production techniques used in each city. Due to the various energy sources and fuels used, the emissions types and quantities generated are also different. All three case study cities reported varying proportions of emissions from different sectors, and their climate strategies are also based on those emissions ratios. However, it is suspected that the amount of emissions will remain different if robust calculations are adopted.

Several dilemmas in boundary setting, emissions factors calculations, and data collection exist vis-à-vis current calculation methods. Due to the national electricity grids used for electricity consumption, some cities such as Stockholm and Copenhagen face difficulties in breaking down the national emissions data. Emission inventories should provide clear instructions on solving such problems. District heating emissions are not specific in the current calculation systems due to the different fuels used in district heating systems, which can be solved by using the best emissions factors for each fuel. In addition, the allocation of district heating fuels in a combined heat and power production $(\mathrm{CHP})$ system can vary greatly depending on the calculation method used (primarily the energy method, the benefit allocation method, or the energy method), which can affect the emissions by a factor of two to three in some cases [28]. In addition, some emissions-such as emissions from agriculture, cooling and refrigerants, electricity for heating, and freight traffic emissions-remain inappropriately calculated due to difficulties in data collection. Yet, individual sector emissions calculation methods can be applied to solve such difficulties. Such practices are not applied in all three case study cities. Cities have attempted to include emissions from airport and shipping, but results show that difficulties arise in how to assess long-distance flights and shipping, because no clear instructions exist for reporting in the current calculation methods for such emissions. For instance, Stockholm Bromma Airport includes aircraft emissions to the height of $915 \mathrm{~m}$ [15]. The city of Copenhagen does not have an airport within its boundary, and, thus, such emissions are not included; Helsinki's Malmi Airport does not have such emissions calculations, but that airport is scheduled to close soon [18]. The primary passenger airport of Helsinki actually lies beyond the city's administrative boundaries. Similarly, emissions from freight traffic, small vehicles within the airport, and small ships are also questionable under the existing emissions calculation methods. Stockholm includes emissions 
from cooking gas leakage, while Helsinki does not since it is not a huge source of emissions within Helsinki [16]. Yet, it is not clear whether Copenhagen included cooking gas leakage emissions in its calculations. Thus, variations exist in the inclusion of types of GHG emissions from several sectors. For instance, nitrous oxide and life-cycle emissions are missing from vehicles in Stockholm, while Helsinki and Copenhagen also excluded such GHG emissions from specific sectors.

Two case study cities also face difficulties defining the baseline year. If different cities designate different baseline years, emissions reductions ratios and the extent of climate-related actions cannot be compared across cities. Applying a common GHG accounting system across cities may solve this issue. Cities also have differences in terms of the sectors included in calculations. In fact, a robust calculation method does not exclude emissions from any sector, but includes all sectors as much as possible. Moreover, all cities excluded indirect emissions from citizens and businesses within city limits. A number of inaccuracies exist in the current emissions accounting systems used by all three case study cities. However, cities can alleviate such uncertainties and improve their data measurement, data collection, and calculation methodologies [7].

Because the cities' climate strategies are generated using emissions scenarios from corresponding cities, each cityinitiated numerous climate strategies based on their emissions calculation results. For instance, the city of Copenhagen included a compensation method to achieve its climate strategies, while Helsinki is considering including this as an option to reach its carbon neutral goal by 2050 . However, this is not the best way to reduce emissions, since the emissions reduction within the cities' geographical area is not large and accounting for such measures remains biased. On the contrary, climate strategies such as carbon taxes or congestion charges surely reduce emissions. However, setting the carbon tax price is difficult due to the various purposes of carbon prices related to subsidizing the purchase of electric vehicles, low carbon fuels, technological behaviors, and the conversion of building heating systems from gas to electric power [34].

Likewise, the cities' climate strategies towards achieving carbon neutrality or becoming fossil-fuel free by a specific time depend on emissions calculations. If calculations are based on the consumption of goods, fuels, and energy, cities may not reach their goals by the specified time because large amounts of emissions are excluded using current accounting systems. Furthermore, the extent of climate actions need to be completed rapidly or alternative climate strategies need to be adopted to nullify any omitted emissions. For instance, Copenhagen's consumption-based emissions are four to five times higher than its production-based emissions; if it must reduce such emissions to zero, Copenhagen may not reach its carbon-neutral goal by 2025 or it must adopt supplementary emissions measures and rapid climate actions. However, consumption-based emissions accounting is currently not required for city reporting, but real emissions are reduced only based on consumption-based emissions particularly in these three case study cities. Thus, the emissions accounting systems currently used must be improved in order to include all possible sectors and to create more robust and transparent calculation methods.

Well-defined system boundaries with clear instructions for GHG emissions remain vital to precise comparisons of inter-city emissions. Cities should either develop comprehensive calculation methods in collaboration with governmental agencies, other municipalities, universities, and research institutions where both direct and indirect emissions of GHGs are included. Alternatively, cities should adopt the GPC standard, a more flexible accounting system to include all direct and indirect emissions across all sectors. This would be relevant for them as they are small jurisdictions with particular administrative structures having limited policy levers and resources available to them to formulate new accounting system. It is comprehended that adopting consumption-based emissions calculations using the GPC standard across all case study cities as well as in other cities globally would improve the quality of current emissions accounting systems and allow for comparisons between the corresponding cities' emissions results. This is because consumption-based emissions accounting system includes missing emissions in the current calculations adopted by these cities. The inclusion of missing emissions to the emissions calculation will ultimately help to formulate appropriate climate policies to reduce significant GHG emissions in the local level. 


\section{Conclusions}

This study shows that all three cities apply non-comparable GHG calculation methods. While they may select between many choices in calculating emissions, they lack a common and widely accepted accounting method that multiple cities can adopt. Currently, the emissions accounting methods used in Helsinki, Copenhagen, and Stockholm are appropriate in terms of IPCC and UNFCC reporting standards. Yet, these methods do not include all emissions generated in the cities. The methods adopted appear to carry double counting errors, difficulties in defining the types and emission boundaries for certain sectors, and complications associated with transparency for some of the data collected. Such problems may misdirect the climate strategies for the cities. Emissions from sectors such as shipping and airport emissions need to be improved. Lack of proper definitions for system boundaries also needs to be addressed. Thus, a well-defined boundary system with clear instructions is vital for GHG emissions calculations. Similarly, a large amount of emissions data missing from calculations results from cities adopting production- or territorial-based emissions calculations methods. This can be resolved by adopting consumption-based emissions calculation methods. The consumption-based emission accounting system calculates all emissions from imported goods and local productions to meet the cities' total economic consumption. Updating the system boundaries, emission factors, and emissions data periodically is imperative to improving the quality of emission calculations. In addition, the emission accounting methods adopted in the cities remain incomparable to one another due to the variations in the calculation methods used. Thus, to resolve such issues, a common emissions calculation method is necessary, such as the method derived from the GPC standard platform. The GPC standard is currently emerging as a popular emissions accounting system in many cities. Alternatively, in order to establish a robust, transparent, and qualitative system boundary, cities may develop comprehensive calculation methods in collaboration with governmental agencies, other municipalities, universities, and research institutions that include both direct and indirect emissions of GHG. However, we recommend that cities adopt GPC standards with an expanded reporting level. To adopt these standards globally, we also recommend updating the EU and United Nations reporting guidelines.

Acknowledgments: Most of the data used in this research were collected from the city of Helsinki, Helsinki Region Environmental Services Authority (HSY), City of Stockholm, and City of Copenhagen. We would like to thank all of those at these organizations, especially Senior Environmental Inspector Jari Viinanen, Environmental Planner Petteri Huuska, and Project Planner Sonja-Maria Ignatius form City of the Helsinki Environmental Centre, Chief advisor on climate and economy Morten Højer from the City of Copenhagen Technical and Environmental Department, Johannes Lounasheimo from the Helsinki Region Environmental Services Authority for sharing their precious time in lengthy discussions. We would also like to thank to Environmental Analyst Emma Hedberg from the City of Stockholm Environmental and Health Department for providing valuable materials to conduct this research.

Author Contributions: Karna Dahal collected the data, performed the analyses and drafted the manuscript; Professor Jari Niemelä provided supervision of all stages and commented on the manuscript.

Conflicts of Interest: The authors declare no conflicts of interest.

\section{Appendix A. Framework for Interviews}

Theme 1: Background on the greenhouse gas (GHG) emissions calculation methods

- Development on the practices of GHG calculation methods

- Cities perspectives on production vs. consumption based calculation methods

- Excluded and included emission sources

- Challenges on the current methods and future developments

Theme 2: Effects of GHG accounting system on climate strategies

- Carbon offsetting and compensation methods

- Emissions trading system

- Emissions reductions plans through current calculation methods 
- Effectiveness of current methods to reduce emissions

\section{Appendix B. Interview Details}

Climate Department, Helsinki Region Environmental Services Authority (HSY)

Interviewer: Karna Dahal

Interviewee: Johannes Lounasheimo (Climate Specialist, HSY)

When: Wednesday 30 March 2016, at 9.00:10:00 am.

Where: Head Office, HSY, Asemapäällikönkatu 3 C, 00520 Helsinki

City of Copenhagen Technical and Environmental Administration

Interviewer: Karna Dahal

Interviewee: Morten Højer (Chief Advisor on Climate and Economy, Climate Unit)

When: Thursday 26 May 2016, at 11:00-11:45 a.m.

Where: Municipality Office, Rådhuspladsen 16, 1550 København V, Denmark

\section{References}

1. IPCC. Human Settlements, Infrastructure and Spatial Planning. In Climate Change. Mitigation of Climate Change. Contribution of Working Group III to the Fifth Assessment. Report of the Intergovernmental Panel on Climate Change; Edenhofer, O., Pichs-Madruga, R., Sokona, Y., Farahani, E., Kadner, S., Seyboth, K., Adler, A., Baum, I., Brunner, S., Eickemeier, P., et al., Eds.; Cambridge University Press: Cambridge, UK; New York, NY, USA, 2014.

2. Greenhouse Gas Protocol. Global Protocol for Community-Scale Greenhouse Gas Emission Inventories. Available online: http://ghgprotocol.org/files/ghgp/GHGP_GPC.pdf (accessed on 11 October 2016).

3. Bulkeley, H. Cities and Climate; Miles, M., Short, J.R., Eds.; Routledge: New York, NY, USA, 2013.

4. Ending Climate Change Begins in the City. Available online: http://www.c40.org/ending-climate-changebegins-in-the-city (accessed on 17 June 2016).

5. Hillman, T.; Ramaswami, A. Greenhouse Gas Emission Footprints and Energy Use Benchmarks for Eight USA Cities. Environ. Sci. Technol. 2010, 44, 1902-1910. [PubMed]

6. Gap Analysis of Greenhouse Gas (GHG) Emissions Inventory Methods for Trondheim Municipality, Trondheim: Climate-Kic. Org. Available online: http://local.climate-kic.org/wp-content/uploads/2016/ 06/D2-Gap-analysis-of-GHG-emissions-inventory-methods.pdf (accessed on 19 June 2016).

7. Jonas, M.; Marland, G.; Winiwarter, W.; White, T.; Nahorski, Z.; Bun, R.; Nilsson, S. Benefits of Dealing with Uncertainty in Greenhouse Gas Inventories: Introduction; Jonas, M., Nahorski, Z., Nilsson, S., Whiter, T., Eds.; Climate Change; Springer: Berlin, Germany, 2009; Volume 103, pp. 3-18.

8. Dodman, D. Blaming cities for climate change? An analysis of urban greenhouse gas emissions inventories. Environ. Urban. 2009, 21, 185-201.

9. EEA. European Union $\mathrm{CO}_{2}$ Emissions: Different Accounting Perspectives; European Environment Agency: Publications Office of the European Union, Luxembourg, 2013.

10. Rydpal, K.; Paciornik, N.; Eggleston, S.; Goodwin, J.; Irving, W.; Penman, J.; Woodfield, M. Chapter 1: Introduction to the 2006 Guidelines. In 2006 IPCC Guidelines for National Greenhouse Gas Inventories; IPCC: Tokyo, Japan, 2006; Volume 1.

11. GHG Protocol. GHG Protocol for Cities. Available online: http://www.ghgprotocol.org/city-accounting (accessed on 13 July 2016).

12. World Resource Institute (WRI). Hundreds of Cities Poised to Replicate Rio's Approach to Measuring and Reducing Emissions. Available online: http:/ /www.wri.org/blog/2014/12/hundreds-cities-poisedreplicate-rio\%E2\%80\%99s-approach-measuring-and-reducing-emissions (accessed on 11 August 2016).

13. Perters, G.P.; Minx, J.C.; Weber, C.L.; Edenhofer, O. Growth in emission transfers via international trade from 1990 to 2008. Curr. Issue 2011, 108, 8903-8908.

14. What are Scope 3 Emissions, How can They be Measured and What Benefit Is There to Organizations Measuring Them? Available online: https://www.carbontrust.com/client-services/footprinting/footprintmeasurement (accessed on 18 August 2016). 
15. Musabasic, A.; Löngren, Ö. Stockholms stads utsläppsberäkningaräkningar av växthusgaser. En rapport från Miljöförvaltningen; Environment and Health Administration: Stockholm, Sweden, 2009.

16. Lounasheimo, J. Green House Calculation method used in the Helsinki Metropolitan Area. Interview: (Karna Dahal, interviewer and Juhannes Lounasheimo, interviewee). 2016.

17. Højer, M. Greenhouse Gas calculation method used in the city of Copenhagen. Interview: (Karna Dahal, interviewer and Morten Højer interviewee). 2016.

18. Viinanen, J.; Ignatius, S.-M. GHG method and climate strategies in the city of Helsinki. Discussion: (Discussions between Karna Dahal, Jari Viinanen and Sonja-Maria Ignatius). Discussion: (Discussions between Karna Dahal, Jari Viinanen and Sonja-Maria Ignatius). 2016.

19. Boiter, B. $\mathrm{CO}_{2}$ Emissions production-based accounting vs consumption: Insights from the WIOD databases. In Proceedings of the Final WIOD Conference: Causes and Consequences of Globalization, Groningen, The Netherlands, April 2012.

20. Cities and Climate Change: Global Report on Human Settlements 2011. Available online: http:/ /unhabitat.org/ books / cities-and-climate-change-global-report-on-human-settlements-2011 (accessed on 5 September 2016).

21. Dahal, K.; Niemelä, J. Initiatives towards Carbon Neutrality in the Helsinki Metropolitan Area. Climate 2016, 4, 36. [CrossRef]

22. Normative Analysis and Preparing the Proposal. Available online: http://www2.uiah.fi/projekti/metodi/ 179.htm (accessed on 15 September 2016).

23. Thacher, D. The Normative Case Study. Am. J. Soc. 2006, 111, 1631-1676. [CrossRef]

24. $\mathrm{CO}_{2}$-Calculator in Danish Municipalities. Available online: http://archive.northsearegion.eu/ files/repository/20131128183232_Denmark_CO2_calculator_EXTENDED_VERSION_2_pdf (accessed on 9 October 2016).

25. Pangerl, E.C. A Comparative Analysis of Copenhagen's and Viena's Climate Targets; Umweltschutz in Wien: Viena, Austria, 2014.

26. KUHILAS-Kuntien Hiilijalanjälkilaskuri. Available online: http://www.kunnat.net/fi/tietopankit/ tapahtumat/aineisto/2012/2012-05-03-ilmasto/Documents/2012-05-04-05-jari_rantsi.pdf (accessed on 13 October 2016).

27. CPH 2025 Climate Plan. Available online: http://kk.sites.itera.dk/apps/kk_pub2/pdf/983_jkP0ekKMyD. pdf (accessed on 17 October 2016).

28. Huuska, P. Conversation with Petteri Huuska from City of Helsinki Environmental Centre about the Greenhouse Gas calculation method in Helsinki. 2016.

29. Hedberg, E. Email Conversation with Emma Hedberg for GHG methodologies in Stockholm. 2016.

30. Ilmansaasteiden Vuosikeskiarvot Pääkaupunkiseudulla 1990-2015. Available online: http://www. helsinginymparistotilasto.fi/ (accessed on 27 October 2016).

31. Shan, Y.; Guan, D.; Liu, J.; Liu, J.; Schroeder, H.; Chen, Y.; Zhang, Q. $\mathrm{CO}_{2}$ Emissions inventory of Chinese cities. Atmos. Chem. Phys. 2016. [CrossRef]

32. Carbon Neutral. Carbon Offsetting Explained. Available online: http://www.carbonneutral.com/resourcehub/carbon-offsetting-explained (accessed on 1 November 2016).

33. Afriat, M.; Rittenhouse, K.; Francis, D.; Sopher, P.; Clara, D.S.; Kouchakiji, K. An Emissions Trading Case Study; International Emissions Trading Association (IETA): Tokyo, Japan, 2015.

34. Cities and Carbon-Emissions Pricing. Available online: http://www.in4c.net/files/Cities-and-CarbonEmissions-Pricing-Final-Report-7.2.15.pdf (accessed on 2 November 2016).

35. Chen, W.Y. The role of urban green infrastructure in offsetting carbon emissions in 35 major Chinese cities: A nationwide estimate. Cities 2015, 44, 112-120. [CrossRef]

36. Urban Access Regulations in Europe. Helsinki not Implemented Congestion Charge. Available online: http:/ / urbanaccessregulations.eu/295-road-charging-not-implemented/1234-helsinki-not-implementedcongestion-charge (accessed on 21 November 2016).

37. Proposal for Helsinki Congestion Charges Moves Forward. Available online: http://yle.fi/uutiset/proposal_ for_helsinki_congestion_charges_moves_forward/5910848 (accessed on 23 November 2016).

38. Helsinki's Climate Roadmap. Helsinki. Available online: https://issuu.com/helsinginymparistokeskus / docs/helsinki_climate_roadmap_20150427 (accessed on 27 November 2016).

39. Global Covenant of Mayors for Climate and Energy. Available online: http:/ /www.compactofmayors.org/ globalcovenantofmayors / (accessed on 23 November 2016). 
40. European Green Capital. Policy and Background. Available online: http://ec.europa.eu/environment/ europeangreencapital/about-the-award/policy-guidance/ (accessed on 30 November 2017).

41. Webb, A.; Coates, D. Biofuels and Biodiversity; Secretariat of the Convention on Biological Diversity: Montreal, QC, Canada, 2012; pp. 65-69.

(c) 2017 by the authors. Licensee MDPI, Basel, Switzerland. This article is an open access article distributed under the terms and conditions of the Creative Commons Attribution (CC BY) license (http:/ / creativecommons.org/licenses/by/4.0/). 